I append a short proof, out of several which may be given. We have to show that

$$
\left(w_{2}+w_{3}\right)^{2 n-1}+\left(w_{4}+w_{5}\right)^{2 n-1} \equiv \mathrm{I} \bmod 2 n-\mathbf{I}
$$

when, and when only $2 n-1$ is prime.

Let $w_{2}, w_{3}, w_{4}, v_{5}$ be the unreal roots of $x^{5}+\mathrm{I} \equiv 0$ and $2 n-\mathrm{I}=$ any odd prime, then we may say

$$
\left(\frac{1+\sqrt{5}}{2}\right)^{p}+\left(\frac{1-\sqrt{5}}{2}\right)^{p}=1 \bmod p
$$

$=\left\{\frac{\mathrm{I}+p k+(\sqrt{ } 5)^{p}}{2^{p}}\right\}+\left\{1-p l-(\sqrt{ } 5)^{p}\right\}=\mathrm{I} \bmod p$ where $p$ is any odd prime.

$=\frac{2}{2 p}+2 p \cdot m=\mathrm{I} \bmod p$ or $\frac{\mathrm{I}+p \cdot m}{2^{p-1}}=\mathrm{I} \bmod p$.

Now, by Fermat's theorem $2^{p-1}-\mathrm{I}=p . n$ when, and when only $p$ is prime. Thus.

$$
p \cdot n-p \cdot n=0 \bmod p
$$

which proves the theorem for any odd prime.

It is also true for $p=2$, since by ordinary work

$$
\frac{1+2 \sqrt{ } 5+5}{4}+\frac{1-2 \sqrt{ } 5+5}{4}=3=I \bmod 2 .
$$

Thus the theorem is universally true for all primes.

It is remarkable that the second factor of the prime series given above is also a function of the prime $p$, viz. :

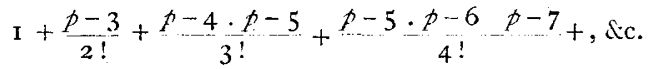

ex. $g r$. the $4^{\text {th }}$ term of the prime series is 29 , thus

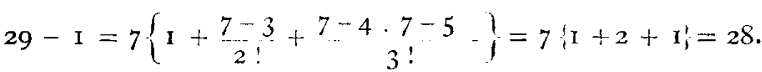

As this communication is somewhat long, I reserve the pron of this.

Aptril 28.

\section{The Effect of Sunlight on the Tints of Birds' Eggs.}

THE beautiful and delicate colours observed on the eggs of birds are not very fast to light, more especially when they belong to the lighter class of colours. Egg-collections should be carefully protected from the light by some covering over the case, when they are not being inspected; otherwise much of their beauty of tint becomes lost in course of time. It is gratifying to notice that in museums and natural history collections this precaution of protecting egg-cases with covers is now almost universally observed. In many instances some of the finest and most characteristic tints of several eggs disappear on exposure to much sunlight. A common example may be found in the beautiful pale blue of the starling's egg (Sturnus vnuloaris). This, on exposure to sunlight for a few days, loses its clear blueness of tone, and becomes purplier, approaching more to the slate tint. Such is also the case with most of the greenish-blue eggs, like those of many sea-birds, the common guillemot's (Uria troile), for instance, the beauty of which largely depends on the clear freshness of its blue tints. The writer, some time ago, made some experiments on the fastness to sunlight of those egg-tints. The method employed was a very simple one, and may be briefly described as follows. Various birds' egrs were selected for experiment, those having decided and wellmarked colours being preferred. These shells were halved lengthwise, care being taken before the operation to divide it so that each half should, as nearly as possible, present the same amount of colouring. One half was kept from the light for future comparison, while the other half was exposed in a glass case to direct sunshine. After various exposures, amounting to one hundred hours' sunshine, each exposed half was then compared with its unexposed counterpart, and the changes in hue carefully noted. Little change was visible in the darker coloured eggs of the olive-brown or chocolate depth, but in the lighter tints, especially among the blues and green-blues, the changes became more marked. Among the darker shades of eggs was the common curlew's or whaup (Numenius arquata), with its dull olive-green spotted with deep shades of brown; and also the lapwing (Vanellus cistatus), which closely resembles in

general appearance that of the curlew. Such deeply-coloured eggs are little altered on exposure to light, unless after very long exposure, when they lose some of their rich warmth of tone, and become a trifle clearer in their ground tints, making them look somewhat bleached. Many sea-birds' eggs have a bluishgreen colour-sea-green it might be called-which, when new and unexposed, is rich and beautiful. This clear tint, however, is lost on exposure, and it assumes a more dingy slate hue. Some of their eggs have a network of white chalk-like incrustation streaked over the bluish ground tint. This may be seen on the egg of the common cormorant (Phalacrocorax carbo). If such shells be exposed for several days to sunlight, and afterwards the white incrustation removed with a knife, the difference produced on the ground tint by exposure becomes at once apparent. The exposed parts will be found of a slaty, cluller hue, more approaching a stone-grey tint ; while the unexposed parts, protected by the incrustation, will reveal the original sea-green tint in all its freshness. Another example is the fair blue egg of the common thrush or mavis (Turdus musicus). This egg when newly laid is of soft light blue of a fine shade, but on exposure it loses much of this clearness of tint, and becomes dull and purply, tending more to a leaden hue. Many similar examples might be given of beautiful shades of blue and bluegreen tinted eggs which all terid to become redder and duller on exposure. The red blotched egg of the fieldfare (Turdus pilaris) fades in this manner, and the red markings assume a lighter rusty-brown hue. The ring ouzel (Turdus torquatus) so well known for its predatory visits to the strawberry-beds, has an egg closely resembling the fieldfare's, both in ground tint and markings, which undergoes the same changes in every respect. One of the commonest eggs is that of the blackbird; it also loses its greenish hue and becomes more of a stone-grey, while its varied markings lose considerably in depth. In the beautiful eggs of the yellow hammer (Emberiza citrinella), so curiously veined and mottled with dark red-brown nver a pale ground, little or no fading was visible after exposure. Its markings may thus be considered fast to light. There are but few coloured eggs which show no appreciable change after so severe an exposure test as Ioo hours' direct sunlight. A good example of a fairly fast-coloured egg is that of the favourite songster the skylark (Alauda arz'ensis). Its eggs vary considerably in colour, but they are always of an indescribable hue, sometimes an ashy brown, or a dark purplish grey, other times more of a greenish tinge. These stand the light very well. The specimens tested looked only a trifle bleached, but those having the greener tinge fade more. One of the prettiest of blue eggs is that of the the common hedge-sparrow. The loss of its clear blue tint to a purplish blue drab was most marked. To illustrate the unstable nature of egrg-colouring in comparison with colours of different origin, various other colours resembling in tint those of the eggs were exposed in a similar manner. These were" distemper" colours, and water colours, painted on paper, and coal-tar colours dyed on wool. The distemper colours were perfectly fast to light ; their colour constituents all being of mineral origin. The water colours examined were both of mineral and vegetable origin; those belonging to the latter faded very considerably. The coal-tar colours selected were mostly of the bluish cast, corresponding to many of the egg tints. The summary of the results obtained might be tabulated as follows :-

\section{Colours examined.}

Distemper colours..

Water colours

Coal-tar colours ...

Egg-shell cólours ...
Result after roo hours' exposure. 100 per cent. fast. 60 , , , 30, 20, , ,

The above results, along with the few common examples which have just been given, readily show that eggs lose much of their delicate and characteristic beauty of tint on being too freely exposed to sunlight.

Rosslyn, Midlothian

\section{Physiological Specific Characters.}

Prof. R. Meldola, in his very suggestive presidential address to the Entomological Society, remarks (Trans. Ent. Soc. for 1896 , Pt. v. p. lxxviii.) :- "At any rate, it appears to me inconceivable that any change of environment requiring a modification of structure of sufficient magnitude to rank as diagnostic in the systematic sense, should not also be accompanied by a 